\title{
Research on Innovation Strategy of Small and Medium-sized Logistics Enterprises in Xi'an Based on the Perspective of Proximity*
}

\author{
Borui Yan \\ School of Economics and Management \\ Chang'an University \\ Xi'an, China 710064 \\ Xi'an FanYi University \\ Xi'an, China 710105
}

\begin{abstract}
With a series of measures to reduce cost and increase efficiency, the internal and external development environment of logistics enterprises in Xi'an have changed a lot. Under the current situation that economic entries into the new normal, the transformation, upgrading and innovation of logistics industry have been accelerated. Improving the competitiveness of small and medium-sized logistics enterprises has great significance to the long-term development of them. By analyzing the innovation environment changes which faced by the small and medium-sized logistics enterprises in $\mathrm{Xi}^{\prime}$ an under the new normal, it investigates the development process of many small and medium-sized logistics enterprises established in Xi'an for more than ten years, and probes into the general innovation and evolution process of them, discusses three modes of innovation: mode innovation, cooperative innovation and independent innovation. And then, from the perspective of proximity, it puts forward some suggestions on the innovation path of small and medium-sized logistics enterprises in Xi'an, in order to provide reference for the longterm development of them.
\end{abstract}

Keywords-small and medium-sized logistics enterprises; innovation evolution path; cooperative innovation; independent innovation

\section{INTRODUCTION}

In recent years, the government has introduced various policies and measures to reduce the cost of enterprise logistics, improves the efficiency of social logistics, and vigorously promotes the transformation and innovation of logistics industry. Xi'an Municipal Party Committee, Xi'an Municipal people's Government combined with the actual economic development of Xi'an, actively carry out the relevant measures of national logistics enterprises innovation and development in the first time. Government is also constantly adjusting support for the development of logistics companies. However, many small and medium-sized

*Project Source: 2017 China Logistics Society, China Logistics and Purchasing Federation Project Plan, Project name: Research on Innovation Environment and Innovation Path of Small and Medium-sized Logistics Enterprises in Xi'an under The New Normal Economy, Subject number: 2017CSLKT3-155 logistics enterprises simply imitate management, in the new innovation environment, it is difficult to break through the old business model, can not accurately locate their own innovation mode. In the face of increasingly fierce competition, many small and medium-sized logistics enterprises face many difficulties, let alone the long-term sustainable development of enterprises.. There have been a lot of researches on enterprise innovation and logistics enterprise innovation. [3]-[10] However, there have not been many achievements in the research of innovation from the angle of proximity. It tries to give the innovation strategy of small and medium-sized logistics enterprises in $\mathrm{Xi}^{\prime}$ an from the perspective of proximity.

\section{THE CHANGING OF INNOVATION ENVIRONMENT FOR SMALL AND MEDIUM-SIZED LOGISTICS ENTERPRISES IN XI'AN UNDER THE NEW NORMAL}

In August 2017, the General Office of the State Council issued "Opinions on How to Further Promote the Logistics to Reduce the Cost and Increase the Efficiency to Promote the Development of the Real Economy" to further promote logistics cost reduction and efficiency enhancement. This paper puts forward some suggestions from seven aspects, to create a good environment for the development of logistics industry, promote the development level of logistics industry and promote the healthy development of real economy.

Shaanxi Province's logistics network through the center of Xi'an to achieve a connection between the north and south, east-west through. As an important city of the Silk Road economic belt, some construction of important international logistics hub platform, such as the construction of Xi'an inland port, the operation of Xi'an railway container center station and the construction of important international logistics hub platform, both of them have played an irreplaceable role in promoting the logistics service of Xi'an's non-silk road economic belt.

In recent years, the scale of Xi'an modern logistics industry has maintained a sustained growth, and its comprehensive strength has been continuously upgraded. In 
2017, the added value of Xi'an logistics industry was 72.8 billion Yuan, an increase of 14.7 Yuan over the previous year, and the added value of the logistics industry accounted for 9.7 percent of GDP. By introducing and nurturing at the same time, Xi'an logistics market has been growing. A large number of logistics and related businesses emerged (at the end of 2017, it reached to more than 10900). In addition, local leading enterprises are also growing rapidly; large enterprises continue to grow in size, including Xi'an International Port Group, Shaanxi Province Logistics Group and others. At the same time, Bester, Asia-Europe and other integrated logistics centers have become a scale. Pai'ang Pharmaceutical Logistics, Shaanxi large-component logistics, Aiju grain logistics and other specialized logistics enterprises develop rapidly. And, large domestic and international logistics enterprises have accelerated their concentration in Xi'an, including JingDong's Global Logistics headquarters, HNA's Modern Logistics Group, Alibaba's Northwest headquarters, Shentong's Northwest area Transit Center, and so on. The situation of logistics industry agglomeration accelerates development has already appeared. [1]

Relies on the expressway "one day traffic circle", the "two vertical, five horizontal and four hubs" railway backbone network and the "one master, four auxiliary" air transport pattern, around industrial agglomeration, consumption orientation and goods circulation, $\mathrm{Xi}$ ' an has opened up freight routes for South Korea, opened up freight trains for Central Asia. Xi'an railway hub has formed a capacity of 200 million tons per year of freight transportation, and the volume of freight transportation in the province has increased from 860 million tons in 2009 to 1.631 billion tons in 2017. A total of 32 logistics parks and some distribution centers have been built.

In addition, the infrastructure construction of Xi'an logistics industry accelerates, the application penetrations of logistics storage, transportation and internet information technology in finance, customer, administrative office and other management have further increased. Internet of things, cloud computing, big data and other new technologies have been applied, logistics and loading and unloading, sorting and packaging, processing and distribution, intelligent labels, tracking and traceability technology and other special equipment have begun to use logistics information platform construction rapidly. In addition, the mechanization of Xi'an logistics enterprises and the popularization rate of standardized equipment have been obviously improved in recent years, which have laid the foundation for the launch of the joint distribution and standardization action plan of commercial logistics in Xi'an.[2]

Manufacturing and trade services have accelerated the separation of goods and commerce, prompted logistics companies more quickly integrate into supply chains. At present, more than $80 \%$ of the manufacturing enterprises and over $95 \%$ of the commercial supermarkets in Xi'an cooperate with third-party logistics companies. The cooperative content includes traditional logistics services such as transportation, warehousing, distribution, and so on, as well as fourth-party logistics services such as logistics system design. Even the logistics system is completely outsourced. Through such cooperation, both supply and demand can not only significantly benefit, but also reduce the social logistics costs. For example, manufacturing and commercial circulation enterprises such as BYD and Shaanxi Coal Chemical Group implemented integrated management of the main and auxiliary industries and supply chain integration, after that, the enterprise logistics cost drops substantially. Some enterprises provide integrated supply chain management services for e-commerce providers to help enterprises to achieve zero-kilometer distribution model, such as Xianyang Airport New City Logistics Park, Xi'an Railway Logistics Distribution Center, Xi'an Port, Shaanxi Hongtaiyang Logistics and warehousing Market.

At present, Xi'an logistics enterprise's main service objects are manufacturing and commerce, there are also some resources integration services for industrial and agricultural trade enterprises, and integrated industrial supply chain services formed jointly with financial institutions. Such as the specialized wholesale market products processing, storage and distribution of supply chain system services. Logistics industry, manufacturing industry, commerce and other industries have developed simultaneously, and the industrial supply chain model has been widely used in the whole city and even the whole province.

At the same time, the continuous development and their wide application in the logistics industry of information technology and supply chain management also have provided low-cost, efficient, diversified and lean logistics services for production and distribution enterprises. It also promotes manufacturing to focus on core business and business sectors and optimize internal division of labor. Moreover, the increasing consumption ability of urban and rural residents and the gradual change of consumption pattern will inject new impetus into the continuous improvement of the service ability and efficiency of the whole society.

At present, the logistics industry in Xi'an has basically formed an enterprise system in which central enterprises, local enterprises, private enterprises and foreign-invested enterprises coexist in various forms. For small and mediumsized logistics enterprises, the competitive situation is becoming more and more serious, so it is inevitable to seek new service modes and innovative ways. We can see that some mechanized and standardized enterprises have strong competitiveness in the market, such as China Merchants Logistics Xi'an Branch, Shaanxi Huangmajia Logistics Distribution Co., Ltd., Xi'an Aiju Group production Base, and China Resources Vanguard Co., Ltd., Lian Group and etc. At the same time, modern HNA logistics and JingDong logistics which entry newly into the market will also had a huge impact on the original structure of the market.

\section{THE EVOLUTION OF INNOVATION PATH OF SMALL} AND MEDIUM-SIZED LOGISTICS ENTERPRISES IN CHINA

Through the investigation of dozens of small and medium-sized logistics enterprises in Xi'an, it analyzes the evolution of innovation path of small and medium-sized logistics enterprises in Xi'an as a typical case of innovation. 
Most of the investigated enterprises have been established for more than ten years, and have experienced different stages of development, relatively mature, can fully show the development process of small and medium-sized logistics enterprises. Through the analysis of the development and innovation process of these small and medium-sized logistics enterprises, it is found that most of the small and mediumsized logistics enterprises are constantly seeking innovation and development in the competition, and constantly pursuing the competitive vitality. They have gone through a road from imitation to independent innovation; the innovation evolution process is shown in "Fig. 1".

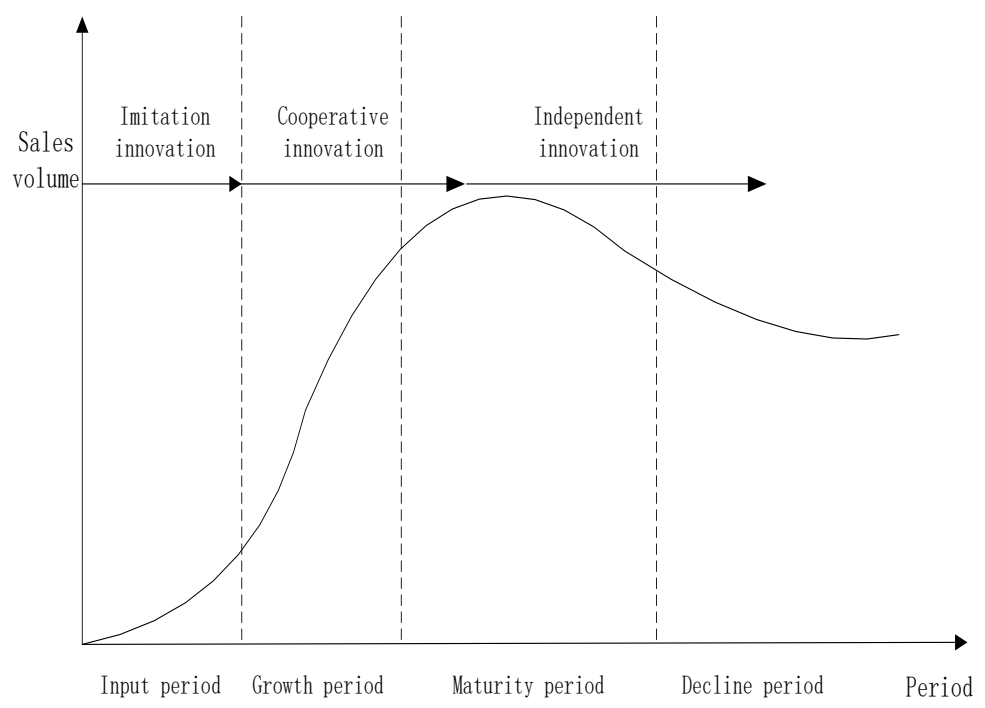

Fig. 1. Innovation and evolution of small and medium-sized logistics enterprises in Xi'an.

\section{A. The Phase Evolution of Innovation Path}

As can be seen from "Fig. 1", most enterprises choose to imitate innovation at the beginning of their establishment. The main reason is that if the emerging enterprises do not have the core competitiveness, then the inexperience will become a short board, only through imitation to survive, on the other hand, it can minimize the risk of innovation. This also reflects that most of the small and medium-sized logistics enterprises in Xi'an have entered the market by imitating market products at the beginning, which is also in line with the development course of most enterprises. With the growth of enterprises, the number of cases of cooperative innovation has increased, and there are some more stable customers on gradual, the forms of cooperative innovation begin to appear, and then, under the background of promotion of constructing an innovative country and an innovative society, more enterprises are willing to adopt the form of independent innovation, and there are many successful cases.

\section{B. Scale Evolution of Innovation Path}

In addition, it is found that the development of enterprise scale will lead to the transformation of innovation path. At the beginning of the establishment, many companies which were investigated have small general scale, products are single, corporate management are not standardized. Then, with the increase of enterprise performance year by year, the product form begin to develop in the direction of diversification, and some enterprises begin to pay attention to market segmentation, and begin to develop towards the direction of scale. The change that follows is the change of innovation mode. And most enterprises will unconsciously change from imitation innovation mode to independent innovation mode. In particular, in recent years, with the strong support of government policies, the scale of small and medium-sized logistics enterprises and the accumulation of technology have increased, with the increase of market scale, many enterprises of small and medium-sized logistics enterprises in Xi'an begin to initiate independent innovation activities and strive to enhance their own core competitiveness.

\section{DISCUSSION ON INNOVATION STRATEGY OF SMALL AND MEDIUM-SIZED LOGISTICS ENTERPRISES IN XI'AN}

\section{A. Evolution of Innovation Path for Small and Medium- sized Logistics Enterprises in Xi'an}

Combines with the evolution of innovation path of small and medium-sized logistics enterprises in Xi'an, it holds that: first, the development of enterprise innovation path is the development process of enterprise innovation ability from scratch; second, there are both active and passive reasons for the turnover of innovation paths, and the ultimate purpose is to adapt to the current or future environment; third, the choice of enterprise innovation path will be affected by many factors, such as organizational environment, entrepreneur, business strategy, enterprise technology and resource level, etc. as shown in "Fig. 2". 

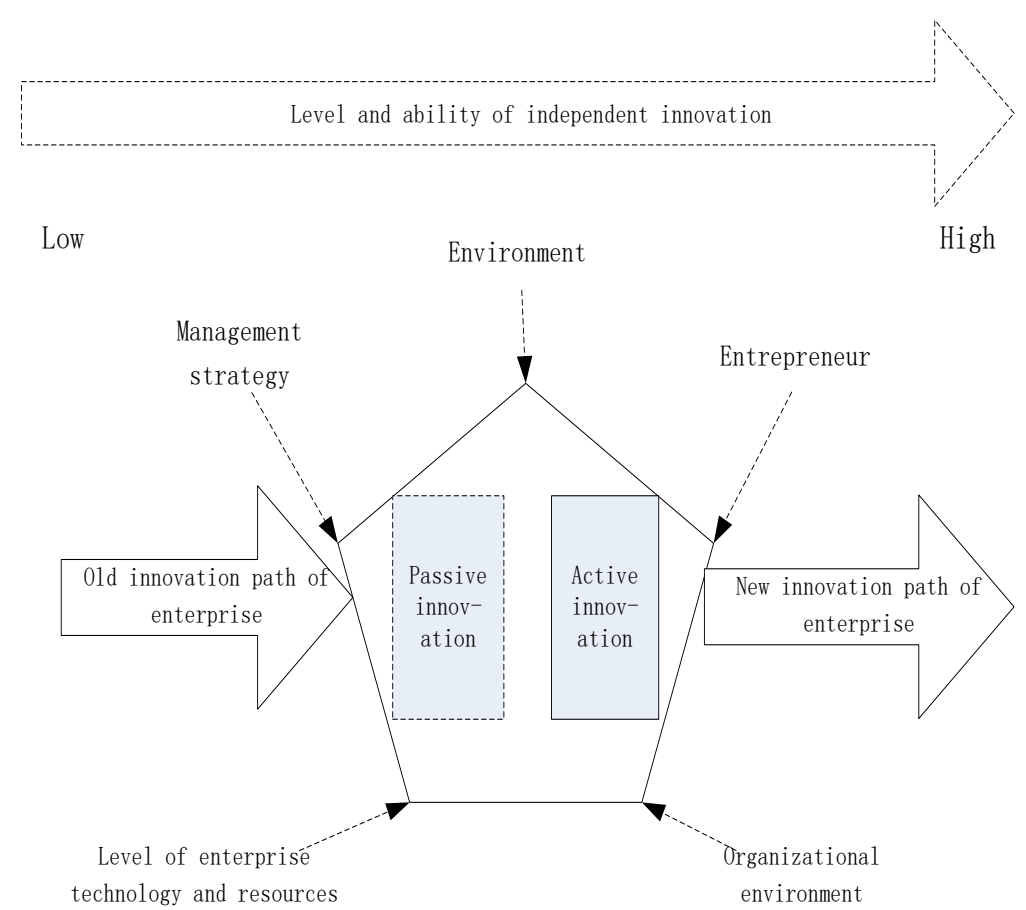

Fig. 2. Evolution model of enterprise innovation path.

According to the investigation, in the innovation process of small and medium-sized logistics enterprises in Xi'an, most of the enterprises mainly adopt the innovation path of introducing and imitating in the beginning of their establishment due to the limitation of technical ability and market conditions. Because the enterprise can use less manpower and capital to obtain more advanced experience, thus saving time and material resources for the enterprise. Later, with the gradual establishment of strategic alliance with partners or the close relationship between them, enterprises began to enter the stage of cooperative innovation. Then, with the improvement of the enterprise's comprehensive ability and its innovation ability, it gradually moves to the road of independent innovation.

It can be seen that the orientation of enterprise innovation path usually has a great relationship with its own strength. Most enterprises begin from imitating innovation, and then gradually adopt the form of strategic alliance for cooperative innovation, when their innovation ability reaches a certain level, they will gradually move toward independent innovation. Of course, the choice of innovation path also has certain relation with market demand; its innovation way is sometimes market-oriented to some extent. [3]

\section{B. Choice of Innovation Path for Small and Medium-sized Logistics Enterprises in Xi'an}

From the previous analysis, we can see that, now, imitation innovation, cooperative innovation and independent innovation are the main innovation paths for small and medium-sized logistics enterprises in Xi'an, and their innovation evolution paths are also these three stages. But we must realize that these three stages are not completely independent. First, imitation innovation and cooperative innovation can coexist. Some enterprises imitating others will increase their own innovation through the way of cooperation. At the same time, with the improvement of innovation ability, many enterprises have both cooperative innovation and independent innovation. What's more, three innovative models coexist in different ways. Imitation innovation can reduce the detours of enterprises, cooperative innovation is helpful for enterprises to learn new technologies and new knowledge, and independent innovation can help enterprises improve their core competitive ability. In addition, the development path of enterprise innovation path is not only from imitation innovation to independent innovation, but also has many paths to choose. For example, some enterprises directly achieve independent innovation from their own accumulation, and there is no cooperative innovation process, but also some enterprises have good independent innovation ability at the beginning of the establishment, and then in cooperation with others, and began to cooperate innovation.

Due to the advantages and disadvantages of each of the three innovative paths, small and medium-sized logistics enterprises in $\mathrm{Xi}^{\prime}$ an can combine various innovative paths to make use of them when they choose, as shown in "Fig. 3". 


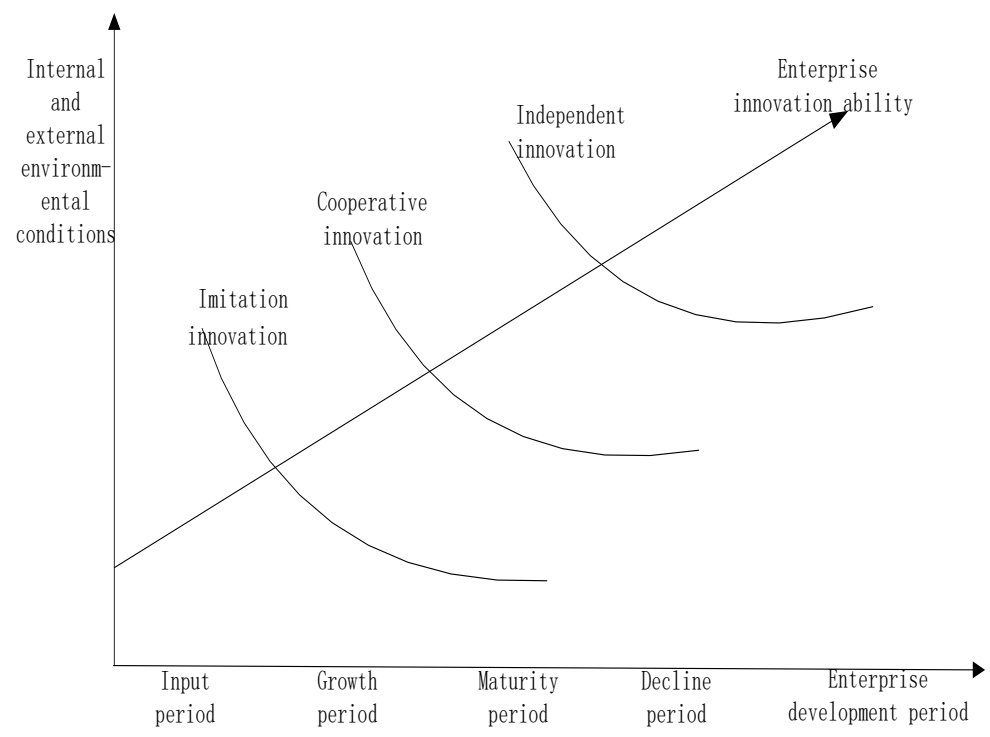

Fig. 3. Enterprise innovation path selection model.

When enterprises choose the path of technological innovation, they should fully understand the internal and external environment of the enterprise, and choose the appropriate innovation path according to the knowledge situation, innovation ability, learning ability, organizational characteristics and capital ability of the enterprise itself. But after all, there are a lot of unpredictable factors may affect the innovation of enterprises. Therefore, after the selection of innovation path, enterprises still need to track in real time, grasp the internal and external changes at any time, and constantly adjust, in order to make the innovative way to better serve the enterprise.

\section{Innovation Strategy of Small and Medium-sized Logistics Enterprises in Xi'an Based on the Perspective of Proximity}

The relationship between proximity, enterprise and industrial innovation has been studied and proved. These studies show that the three dimensions which are geographical proximity, organizational proximity and technological proximity of proximity, play an important role in the construction of enterprises and regional innovation systems.[11]-[20]

Specifically, when different economic entities are geographically adjacent, they can obtain more knowledge resources as their innovation input from the agglomeration of economic activities, especially conducive to the acquisition of tacit knowledge. Organizational proximity is the degree to which enterprises, industries or regions share a relationship space, which indicates the close relationship between the organizational subjects and includes the similarities of the subjects in culture, institution, society and so on. By organizing proximity, enterprises can achieve better interaction and learning, and have a reasonable constraint mechanism to ensure the smooth flow of knowledge. Technological proximity is the similarity of the knowledge base for enterprises, industries or regions, and is the premise of communication between the main bodies.

Many experiences show that in the process of innovation, it is difficult for small and medium-sized logistics enterprises to succeed alone, so it is necessary to make proper use of proximity to contribute to their innovative activities. Therefore, from the perspective of proximity, the following strategies can be adopted in the innovation of small and medium-sized logistics enterprises in Xi'an.

First, join the industrial cluster to promote enterprise innovation. Industrial clusters emphasize the interrelation and interaction among the main bodies of enterprises, and usually adapt to the local social and cultural environment, and its social capital mobility is good. Forming a cooperative network with the enterprises in industrial clusters can promote the better flow of resources such as capital and information, and at the same time, it can be better used by innovative enterprises. This also reflects the model of cooperation and innovation. Of course, in the innovation of cooperation, we should pay attention to the construction of perfect credit system and promote the sustainable innovation of enterprises by realizing open competition.

Second, encourage innovative talent innovation. Enterprises should be good at making use of internal and external innovative talent resources with innovative experience or ability, issue specific innovation incentive policies, encourage internal personnel to innovate, at the same time, willing to spend capital to introduce external innovative talent resources. Start from inside and outside, two-pronged approach; bring more innovation vigor for enterprise.

Third, use temporary geographical proximity to acquire innovative knowledge. Temporary geographical proximity refers to economic relations with the outside world through short-term visits, meetings and other forms of 
communication, rather than the permanent proximity of economic subjects in geographical location. This also reflects the trade exchange, all kinds of related exhibitions in the important role of enterprise innovation.

\section{CONCLUSION}

From the innovation path of small and medium-sized logistics enterprises in $\mathrm{Xi}$ 'an, it can be seen that the evolution of enterprise innovation path is closely related to enterprise scale and market changes. The innovation path of most enterprises is from imitation innovation, cooperative innovation to independent innovation. Under the background of advocating the construction of an innovative country and an innovative society, with the increasingly fierce competition environment, more and more enterprises realize the importance of innovation and are willing to adopt cooperative innovation and independent innovation. Small and medium-sized logistics enterprises in Xi'an can choose the appropriate innovation mode according to the development period of the enterprises and the quality of the internal and external environment of the enterprises. Of course, because each of them has advantages and disadvantages, Xi'an small and medium-sized logistics enterprises can choose it combine a variety of innovative ways to use. At the same time, from the perspective of proximity, the innovation strategies of small and mediumsized logistics enterprises in Xi'an mainly include three aspects: joining industrial clusters, innovating with innovative talents and acquiring innovative knowledge by temporary geographical proximity.

There are still some aspects worth discussing, such as how to construct and perfect the corresponding credit system in the industrial cluster, how to realize the open competition better, and how to better balance the relationship between good material input and manpower input in enterprise innovation.

\section{REFERENCES}

[1] Xi'an Municipal People's Government. Circular of The People's Government of Xi'an on Printing and Issuing The Development Plan of The Modern Logistics Industry in Grand Xi'an (2018-2021) [EB/OL].

http://www.xa.gov.cn/ptl/def/def/index_1121_6774_ci_trid_2932988. html. 2018-10-19.

[2] Anonymous name. Investigation on the Development of Logistics Industry in Shaanxi Province [EB/OL].
[n https://wenku.baidu.com/view/a620d6a4f9c75fbfc77da26925c52cc58 bd690d6.html..2018-10-19.

[3] Chen Shasha. Research on Technology Innovation Path of Small And Medium-sized Enterprises in Zhejiang Province [D]. Hangzhou: Zhejiang University of Technology, 2008.

[4] Bo Yang. Empirical Research on The Factors Affecting Core Competence Evolution of Logistics Enterprises Based on Service Innovation [A]. Research Institute of Management Science and Industrial Engineering. Proceedings of 2017 International Conference on Humanities Science, Management and Education Technology (HSMET 2017)[C]. Research Institute of Management Science and Industrial Engineering. 2017:5.

[5] Xia Yulin. Marketing Innovation of Logistics Enterprise under the "Internet +" era [A]. AEIC Academic Exchange Information Centre, China. Advances in Humanities and Social Science Research
(Advances in Social Science, Education and Humanities Research Vol.91)[C] AEIC Academic Exchange Information Centre, China. 2016:4

[6] Lu Chunhua. Research on Innovation Path of Common Logistics Business Model Based on Market Segmentation [J]. Commercial Economics Research, 2016 (05): 71-73.

[7] Shi Yueyao. Research on Innovation Path of Logistics Enterprise's Business Model under High Competition Environment [J]. Research on Coal economy, 2015, 35 (08): 9-12.

[8] Xue TIAN. Research on Relationship of Network Embeddedness and Logistics Enterprises Service Innovation Performance - Based on the Dynamic Capability [A]. International Research Association of Information and Computer Science. Proceedings of 2015 International Conference on Social Science, Education Management and Sports Education (SSEMSE 2015) [C]. International Research Association of Information and Computer Science. 2015:7.

[9] Liu Dan. Service Innovation Mode and Path of Logistics Enterprises [J]. Chinese Circulation Economy, 2014, 28(04):77-84.

[10] Yang Min. Analysis on Innovation Path of Logistics Enterprises in China from the Perspective of Service Flow [J]. Business Age, 2010 (26): 40-41.

[11] Michael Porter. National Competitive Advantage [D]. Beijing: Huaxia Press, 2002.139-150.

[12] Bottazzi L. Globalization and Local Proximity in Innovation: a Dynamic Process [J]. European Economic Review, 2001, 45(46):731-741

[13] Beugelsdijk S,Cornet M. 'A far friend is worth more than a good neighbour': Proximity and Innovation in A Small Country[J]. Journal of Management and Governance, 2002,6(2):169-188.

[14] Rolf S. Entrepreneurship, Proximity and Regional Innovation Systems [J]. Journal of Economic \& Social Geography, 2007, 98(5):652-666.

[15] Wang Xiaobin, Li Fugang. The Function Mechanism of Geographical Proximity in Regional Innovation and Its Enlightenment [J]. Economic Geography, 2007, 27(4):543-552.

[16] Li Zhenqiang. A Study on the Impact of Knowledge Spillover Proximity on Firms, Industries and Regional Innovation [D]. Changsha: Hunan University, 2010

[17] Liu Fengchao, Nan Ding. The Influence of Geographical Proximity on Enterprise Innovation Performance [J]. Scientific Studies, 2018, 36(09): 1708-1715.

[18] Zhang Yalui, Ma Ding. The Impact of Multidimensional Proximity on Innovation Performance - Taking the Iron and Steel Industry as an Example [J]. Journal of Accounting, 2018 (12): 121-128.

[19] Zhang Fu. A Study on the Factors Influencing the Integration of Producer Services and Manufacturing Industry from The Perspective of Multidimensional Proximity [D]. Guangxi University, 2017.

[20] Wang Tao, Wang Hui. The Influence of Geographical Proximity on Enterprise Innovation Performance: Based on Enterprise Capability [J]. Business Economy and Management, 2017(02): 25-32. 